\title{
Virtual ED: Utilisation of a Discrete Event Simulation-Based Framework in Identifying "Real-Time' Strategies to Improve Patient Experience Times in an Emergency Department
}

\author{
Waleed Abo Hamad \\ Technological University Dublin, waleed.abohamad@tudublin.ie \\ John Mclnerney \\ Mater Hospital, jmcinerney@mater.ie \\ Amr Arisha \\ Technological University Dublin, amr.arisha@tudublin.ie
}

Follow this and additional works at: https://arrow.tudublin.ie/buschmarart

Part of the Business Administration, Management, and Operations Commons, and the Other Operations Research, Systems Engineering and Industrial Engineering Commons

\section{Recommended Citation}

Abo-Hamad, W., Mclnerney, J., Arisha, A.:Virtual ED:Utilisation of a Discrete Event Simulation-Based Framework in Identifying 'real-time' Strategies to Improve Patient Experience Times in an Emergency Department. Emergency Medicine Journal, 2011;28:A3-A4 doi:10.1136/emermed-2011-200617.7

This Article is brought to you for free and open access by the School of Marketing at ARROW@TU Dublin. It has been accepted for inclusion in Articles by an authorized administrator of ARROW@TU Dublin. For more information, please contact arrow.admin@tudublin.ie, aisling.coyne@tudublin.ie,gerard.connolly@tudublin.ie. Funder: Technological University Dublin

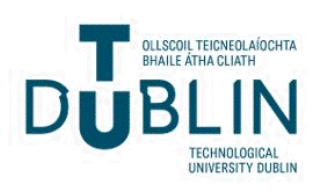




\title{
'Virtual ED' - Utilisation of a Discrete Event Simulation-based Framework in identifying 'real-time' strategies to improve Patient Experience Times in an Emergency Department
}

\author{
Waleed Abohamad ${ }^{1}$ \\ John McInerney ${ }^{2}$
${ }^{1} 35$ Group - College of Business, DIT, Ireland
${ }^{2}$ Mater Hospital, Dublin, Ireland

Amr Arisha ${ }^{1}$

\section{Introduction}

Emergency Department (ED) overcrowding and associated excessive Patient Experience Times (PETs) have proven deleterious impacts on patient mortality, morbidity and overall length of hospital stay. Health systems constantly seek cost-effective organizational strategies to reduce ED crowding and improve patient outcomes, but complex change implementation is constrained by the necessity of maintaining concurrent safe patient-care.

Computer modeling in a 'virtual reality' has been successfully utilized in industries outside medicine, in providing innovative 'real-time' solutions to outdated practices. Therefore a bespoke 'Virtual ED' computer model, based on a Discrete Event Simulation (DES) -Based Framework was constructed to determine the best simulation scenarios needed for effective 'real-time' strategies to improve PETs in a Dublin teaching hospital ED. The three simulation scenarios tested were:-

1. Increasing medical staffing

2. Increasing assessment space

3. Enforcing the national 6-hour boarding limit

\section{Methods}

A collaborative interactive decision support model was constructed to analyse patient flow through the ED, considering the variability in patients' arrival rate, the complexity levels of patients' acuity, and the dynamic interactions between key resources (e.g. clinical staffing, physical capacity, \& spatial relationships). ED Process Mapping utilised IDEFO, for modelling complex systems in a hierarchical form and Extend Suite v.7 software was used to develop the DES- based framework model.

Historical, anonymised ED patient data of 59,986 patient episodes (tracking times, indirect acuity \& clinical resource utilisation) was analysed from the 'real-time' ED Information System. Baseline ED Key Performance Indicators (KPIs), PETS and resource utilisation was determined for comparison with the DES model.

Distinct study scenario variables (Table 1) were added to the DES model and run for 3 month continuous blocks to eliminate confounders. Continuous verification and validation of the ED simulation model was ensured by using Kolmogorov Smirnov goodness of fit test with a $5 \%$ significance level. The ultimate results of the simulation model were validated using three techniques; face validation, comparison testing, and hypothesis testing, with the deviation between actual and simulated results ranging from $1 \%$ to $9 \%$ with an average of only $5 \%$ deviation.

Table 1 Simulation variables for base scenario and scenario 1,2, and 3

\begin{tabular}{lccc}
\hline \multicolumn{4}{c}{ Model Control variables } \\
\hline & Access Block & Physical capacity & Additional physician shift \\
Base Line & Yes & 13 & - \\
Scenario 1 & Yes & 19 & - \\
Scenario 2 & Yes & 13 & SHO \\
Scenario 3 & No & 13 & - \\
\hline
\end{tabular}




\section{Results}

The 'Virtual ED' model shows that adoption of the cost-neutral scenario 3 (Table 2) has the greatest impact on PETs at every stage, especially amongst patients who are ultimately discharged directly from ED care (48\% improvement PETs). Scenario 3 reduces an over-reliance on overstretched nursing resources, whilst improving the utility of physicians. Furthermore whilst scenario 3 improves the PETs of boarders, the more expensive Scenarios 1 and 2 have negligible impact on ED boarding times.

Table 2 Simulation results of scenario 1,2 , and 3

\begin{tabular}{|c|c|c|c|c|c|c|c|c|c|c|}
\hline \multicolumn{2}{|c|}{ Key Performance Indicators (KPIs) } & \multirow{2}{*}{$\begin{array}{l}\begin{array}{l}\text { Base } \\
\text { Line }\end{array} \\
2.96\end{array}$} & \multicolumn{3}{|c|}{ Scenario 1} & \multicolumn{3}{|c|}{ Scenario 2} & \multicolumn{2}{|c|}{ Scenario 3} \\
\hline $\begin{array}{c}\text { Avg. } \\
\text { Waiting } \\
\text { Time (hrs) }\end{array}$ & First Clinical Contact & & 2.50 & $15 \%$ & $\downarrow$ & 2.80 & $5 \%$ & $\downarrow$ & 1.80 & $39 \%$ \\
\hline $\begin{array}{l}\text { Avg. } \\
\text { Patient }\end{array}$ & Discharged Patients & 10.23 & 8.40 & $18 \%$ & $\downarrow$ & 9.80 & $4 \%$ & $\downarrow$ & 5.30 & $48 \%$ \\
\hline $\begin{array}{l}\text { Experience } \\
\quad(\mathrm{hrs})\end{array}$ & Admitted Patients & 21.30 & 18.20 & $15 \%$ & $\downarrow$ & 19.80 & $7 \%$ & $\downarrow$ & 5.70 & $73 \%$ \\
\hline \multirow{5}{*}{$\begin{array}{l}\text { Resource } \\
\text { Utilisation }\end{array}$} & Doctor & $81 \%$ & $84 \%$ & $4 \%$ & $\uparrow$ & $73 \%$ & $10 \%$ & $\downarrow$ & $86 \%$ & $7 \%$ \\
\hline & General Nurse & $82 \%$ & $87 \%$ & $7 \%$ & 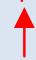 & $83 \%$ & $1 \%$ & $\hat{\uparrow}$ & $74 \%$ & $10 \%$ \\
\hline & Resuscitation & $91 \%$ & $86 \%$ & $6 \%$ & $\downarrow$ & $91 \%$ & $0 \%$ & & $87 \%$ & $5 \%$ \\
\hline & Major Trolleys & $94 \%$ & $82 \%$ & $13 \%$ & $\downarrow$ & $92 \%$ & $2 \%$ & $\downarrow$ & $85 \%$ & $10 \% \downarrow$ \\
\hline & Ambulatory Care Unit & $93 \%$ & $75 \%$ & $19 \%$ & $\downarrow$ & $94 \%$ & $2 \%$ & $\hat{\varphi}$ & $83 \%$ & $11 \%$ \\
\hline $\begin{array}{l}\text { Avg. } \\
\text { Distance }\end{array}$ & Doctor & 3.24 & 3.63 & $12 \%$ & $\hat{4}$ & 2.83 & $13 \%$ & $\downarrow$ & 3.91 & $21 \%$ \\
\hline $\begin{array}{l}\text { Travelled } \\
(\mathrm{km} / \text { day })\end{array}$ & Nurse & 6.48 & 7.32 & $13 \%$ & 4 & 6.55 & $1 \%$ & $\hat{4}$ & 5.34 & $18 \%$ \\
\hline \multicolumn{2}{|c|}{$\begin{array}{l}\text { Avg. Number of Patients in Waiting } \\
\text { Room }\end{array}$} & 15.47 & 12.62 & $18 \%$ & $\downarrow$ & 14.10 & $9 \%$ & $\downarrow$ & 2.44 & $84 \%$ \\
\hline
\end{tabular}

\section{Conclusions}

The use of an interactive DES-based framework accurately determines the best simulation scenarios and identifies the most effective 'real-time' strategies in improving PETs in an ED environment. Whilst increasing medical staffing or trolley numbers might seem intuitively beneficial to overall PETs, our 'Virtual ED' reveals that simply enforcing the national KPI 6-hour boarding limit for EDs, would have a greater impact on reducing PETs for all ED patients than increasing medical staff or assessment cubicles..

Before instigating potentially ineffectual and costly 'real-time' strategies, the construction of novel simulation scenarios in a 'Virtual ED' may allow implementation of more effective yet inexpensive bespoke alternatives. 